\title{
A discórdia das canetas: um estudo do ethos em páginas de cunho político no Facebook
}

\author{
The discord of pens: a study of ethos in political pages on Facebook \\ Cristina Rothier Duarte ${ }^{1}$ \\ Francisco Vieira da Silva² \\ ${ }_{1}$ Universidade Federal da Paraíba, João Pessoa, Paraíba, Brasil. \\ 2 Universidade Federal Rural do Semi-Árido, Mossoró, Rio grande do Norte, Brasil.
}

\begin{abstract}
Resumo: Este artigo tem como objetivo geral analisar o ethos de duas páginas criadas no Facebook, Caneta desmanipuladora e Caneta desesquerdizadora, no intuito de investigar como tais páginas criam uma imagem de si a partir de enunciações publicadas em suas timelines. Para a realização deste estudo, tomamos como aporte teórico os estudos da Análise do Discurso de linha francesa, especialmente, o conceito de ethos discursivo trabalhado por Maingueneau, bem como o exame sobre o Facebook empreendido por Emediato. Metodologicamente, este trabalho se inscreve no âmbito de um viés descritivo-interpretativo de cunho qualitativo. Como resultado, verificamos, com base na análise do corpus, como dois enunciadores, que, a priori, apresentam propostas semelhantes, podem criar imagens de si distintas, a partir do ethos discursivo.
\end{abstract}

Palavras-chave: análise do discurso; ethos discursivo; Facebook.

\begin{abstract}
This article has as objective to analyse the ethos of two pages created on Facebook: Caneta desmanipuladora and Caneta desesquerdizadora, in the intention of investigating how they create an image of themselves from enunciations published in their timelines. For the realization of this study, we take as theoretical support the studies of the Discourse Analysis of French line, specially, the concept of ethos worked by Maingueneau, as well as the Facebook exam undertaken by Emediato. Methodologically, this study is registered in an interpretativedescriptive slant of qualitative hallmark. As result, we check, on basis of the analysis of the corpus, as two enunciators, which, a priori, group together, can create images of themselves distinct from the discursive ethos.
\end{abstract}

Keywords: discourse analysis; discursive ethos; Facebook.

\section{Introdução}

O cenário político do Brasil contemporâneo tem cada vez mais agenciado certa necessidade de expressar suas ideias e seus posicionamentos políticos e ideológicos. Nesse contexto, sites como o Facebook têm contribuído no sentido de se apresentar também como um espaço para esse tipo de debate. O Facebook constitui um site de redes sociais (SRS) que, de acordo com Boyd e Ellison (2007), é formado basicamente por três elementos: possibilita a construção de um perfil pelo usuário, permitindo, por seu turno, conectar-se com outros usuários, de maneira a visualizar a rede e as ações do dono desse perfil como e as de outrem. Autores como Recuero (2010) destacam que os
SRS não constituem redes sociais em si, mas plataformas por meio das quais estas se manifestam na web.

No final do ano de 2017, o Facebook anunciou que possui mais de dois bilhões de usuários em todo o globo $^{1}$. Desse total, o Brasil detém cerca de cem milhões desses internautas, sendo o terceiro país com o maior número de contas ativas no mundo. Essa expressividade numérica atesta os efeitos da cultura da hiperconexão nos modos por meio dos quais os sujeitos se mostram na web. Considerando que estar conectado constitui uma obrigatoriedade no tempo presente, ou nas palavras

\footnotetext{
1 Informação disponível em: <http://link.estadao.com.br/noticias/ empresas,facebook-alcanca-2-07-bilhoes-de-usuarios-no-mundo, 70002069551>. Acesso em: 16 abr. 2018.
} 
de Lemos (2010), uma febre de interatividade, convém investigar os desdobramentos dessa exigência no tocante à construção das subjetividades e à formação das sociabilidades em rede. Conforme destaca Couto (2014, p. 282): “A principal característica da vida conectada é que cada um encontra o meio necessário, a própria rede, para promover a cultura do fazer conjunto". No interior de um ambiente eminentemente colaborativo, fervilham diversas possibilidades de troca e de interações entre os sujeitos, os quais podem se reunir, por meio de práticas sociais associativas (LEMOS, 2003), no intuito de produzirem determinado tipo de conteúdo que os interessa, pois partilham de um mesmo posicionamento discursivo, notadamente em relação às afinidades políticas e, como corolário, às divergências intrínsecas a esse debate.

No que diz respeito ao engajamento político, podemos notar, no Facebook, diversas maneiras por meio das quais os usuários comportam-se em seus perfis ou no de outro usuário: alguns se mantêm supostamente neutros, no sentido de não manifestarem uma opinião sobre o tema; outros participam, adotando uma atitude sóbria e coerente; enquanto outros preferem uma forma mais emocional de enunciar ou de militar em favor de uma causa ou de um partido. Para além desse locus, atualmente, não é rara a criação de páginas, as quais na convergência digital (JENKINS, 2009) com outros sites da rede, objetivam tratar quase que exclusivamente de questões políticas, ensejando mais um espaço para os usuários debaterem da forma como desejarem. Nesse âmbito, figuram páginas como Caneta desmanipuladora e Caneta desesquerdizadora, as quais se propõem, tomando como base enunciações de jornais, revistas e sites de notícias, mostrar um suposto discurso verdadeiro que se "mascara" a partir dos interesses político-partidários da mídia.

Considerando que o sujeito, no momento em que enuncia, cria uma imagem de si, de maneira a delinear um ethos (ethos discursivo) que nem sempre se confunde com a imagem que o locutor se propõe a produzir (ethos dito), neste artigo, objetivamos pensar os indícios discursivos responsáveis pela construção de imagens de si em páginas que tratam de questões políticas, a partir de um olhar que visa "esclarecer" inverdades e posições ideológicas de jornais e revistas de expressiva circulação nacional. Cada uma das páginas, compartilhando de posicionamentos discursivos discrepantes, enxergam a chamada "grande mídia" como uma instância discursiva que deturpa, manipula e manobra os fatos e acontecimentos veiculados.

A partir de oito publicações selecionadas nas duas páginas em estudo, buscamos compreender como elas constroem o ethos discursivo, bem como analisamos comparativamente como se comporta esse ethos discursivo diante do ethos dito de ambos os enunciadores, tomando como aporte teórico estudos de Emediato (2015) sobre o Facebook, e de Maingueneau $(2004 ; 2016)$ sobre o ethos dito e ethos discursivo. A metodologia empregada foi a pesquisa descritiva-interpretativa de cunho qualitativo, da qual nos utilizamos para a realização da revisão da base teórica em Análise do Discurso de linha francesa, com vistas ao estudo das páginas que selecionamos no Facebook.

Do ponto de vista estrutural, este artigo organizase nos seguintes moldes. Além desta seção de cunho introdutório, o texto compõe-se de mais três tópicos, quais sejam: o tópico a seguir discute teoricamente acerca do ethos sob o horizonte investigativo de Maingueneau (2004; 2016), relacionado com uma reflexão acerca das possibilidades sociotécnicas que o Facebook oferta para a constituição de uma imagem de si. Na seção posterior, o foco recobre as análises das publicações das páginas Caneta desmanipuladora e Caneta desesquerdizadora, tomando como base o arsenal teórico-metodológico da seção teórica. Finalmente, no último tópico, esboçamos alguns apontamentos com efeitos conclusivos para as discussões aqui suscitadas.

\section{A construção da imagem no Facebook: abordagem teórica sobre o ethos discursivo}

Conforme apresentamos anteriormente, neste artigo, tratamos da análise de publicações das páginas, Caneta desmanipuladora e Caneta de desesquerdizadora, selecionadas no Facebook, a fim de identificamos os recursos empregados por esses enunciadores de forma a construir o seu ethos discursivo partindo de suas enunciações nessa rede social. Para tanto, preliminarmente, apresentamos alguns conceitos teóricos, pertinentes à referida análise e necessários para a sua compreensão, empregados na Análise do Discurso de linha francesa, mais especificamente, os trabalhados por Dominique Maingueneau.

Nessa perspectiva, o discurso não se limita ao dito. O sujeito ao enunciar, embora, muitas vezes, possa não perceber conscientemente o que acontece no entorno desse ato, apresenta uma maneira de dizer que possibilita, no âmbito do coenunciador, a construção de uma imagem sua. Assim, seja mediante um texto escrito ou oral, seja em um periódico ou em uma conversa informal, o modo de enunciação (AMOSSY, 2016) contribui significativamente para a elaboração do perfil psicológico (o caráter) e corporal (a corporalidade) desse enunciador.

No Facebook, quando o sujeito cria uma conta e passa a publicar os chamados posts, os coenunciadores - amigos ou público em geral, dependendo de sua configuração de privacidade do perfil - procedem com 
a construção da imagem do enunciador, tomando como referência o modo como se mostra esse enunciador em seu discurso. Maingueneau considera que "[...] o texto escrito possui, mesmo quando o denega, um tom que dá autoridade ao que é dito. Esse tom permite ao leitor construir uma representação do corpo do enunciador (e não, evidentemente, do corpo do autor efetivo)" (2004, p.98). Emerge, assim, ainda segundo o autor, uma instância subjetiva cujo papel é ser fiador do que é enunciado.

Essa dimensão subjetiva, dotada de um caráter e uma corporalidade, "[...] provém de um conjunto difuso de representações sociais valorizadas ou desvalorizadas, sobre as quais se apoia a enunciação que, por sua vez, pode confirmá-las ou modificá-las" (MAINGUENEAU, 2004, p. 98-99). Assim,

[a] maneira de dizer autoriza a construção de uma verdadeira imagem de si e, na medida que o locutário se vê obrigado a depreendê-la a partir de diversos índices discursivos, ela contribui para o estabelecimento de uma inter-relação entre o locutor e seu parceiro. Partindo da eficácia da palavra, a imagem quer causar impacto e suscitar a adesão. Ao mesmo tempo, o ethos está ligado ao estatuto do locutor e à questão de sua legitimidade, ou melhor, ao processo de sua legitimação pela fala (AMOSSY, 2016, p, 16-17).

Como se vê, o ethos discursivo não vem explicitado no discurso, pois ao enunciar, por exemplo, sobre política, o enunciador não diz (ou espera-se que não diga) explicitamente que domina a linguagem e o conteúdo, e nem que sabe se expressar adequadamente, mas o interlocutor, tomando como base o modo com que aquele faz, compreende que é dotado de um ethos x, e não de um ethos y.

Ainda que o enunciador afirmasse, em seu discurso, possuir tal caráter ou personalidade (ethos dito), o coenunciador, mesmo assim, teria condições, partindo dos indícios discursivos, de confrontar ambos os planos dos ethé (dito e discursivo), concluindo que um endossa o outro ou o nega. Em outras palavras, Maingueneau (2016, p. 70) explica que "[...] o ethos se desdobra no registro do 'mostrado' e, eventualmente, no do 'dito'. Sua eficácia decorre do fato de que envolve de alguma forma a enunciação sem ser explicitado no enunciado."

O processo de construções do ethos, de acordo com o que podemos perceber, embora parta do discurso formulado pelo enunciador, dá-se efetivamente no âmbito do coenunciador, visto que "[o] texto não é para ser contemplado, ele é enunciação voltada para um coenunciador que é necessário mobilizar para fazêlo aderir 'fisicamente' a certo universo de sentido." (MAINGUENEAU, 2016, p. 73).
Maingueneau (2016) denomina de incorporação a forma como o coenunciador se relaciona com o ethos e entende que a incorporação pode atuar em três registros indissociáveis:
A enunciação do texto confere uma corporalidade ao fiador, ela lhe dá um corpo.
$\mathrm{O}$ coenunciador incorpora, assimila um conjunto de esquemas que correspondem à maneira específica de relacionar-se com o mundo, habitando seu próprio corpo.
Essas duas primeiras incorporações permitem a constituição de um corpo, da comunidade imaginária que aderem a um mesmo discurso (MAINGUENEAU, 2016, p. 73).

Nas redes sociais digitais, meio em que se dão os enunciados analisados neste artigo, o ethos discursivo desempenha um importante papel no que diz respeito ao impacto suscitado nos coenunciadores e à sua adesão ao enunciado, de maneira que as escolhas lexicais, sintáticas, o domínio ortográfico, o conhecimento do enunciador sobre determinado assunto, ou sua falta, por exemplo, irão interferir diretamente na forma como seu discurso será recebido por seu destinatário, que poderá aderi-lo ou rechaçá-lo.

Além da compreensão acerca do ethos discursivo, precisamos também entender três outros conceitos que circundam o discurso, portanto, pertinentes para o nosso estudo: cena englobante, cena genérica e cenografia:
A 'cena de enunciação' integra de fato três cenas, que proponho chamar de 'cena englobante', 'cena genérica' e 'cenografia'. A cena englobante corresponde ao tipo de discurso; ela confere ao discurso seu estatuto pragmático: literário, religioso, filosófico... A cena genérica é a do contrato associado a um gênero, a uma 'instituição discursiva': o editorial, o sermão, o guia turístico, a visita médica... Quanto à cenografia, ela não é imposta pelo gênero, ela é construída pelo próprio texto: um sermão pode ser enunciado por meio de uma cenografia professoral, profética etc. (MAINGUENEAU, 2016, p. 75).

Isso significa dizer que, ao enunciar, o discurso não se dá no vazio, pois há todo um contexto que envolve o dito pelo enunciador. A título de exemplo, imaginemos um palestrante do meio acadêmico. Em sua apresentação, será construído um ethos coerente com o ambiente em que se dá o discurso, as escolhas lexicais, as construções sintáticas, sua entonação, evidentemente, não serão as mesmas que se daria em uma conversa informal com amigos íntimos, porque a cena englobante gira em torno de um discurso de cunho científico, a cena genérica é exposição de algum conteúdo (apresentação de resultado de uma pesquisa, por exemplo), e a cenografia, em 
regra, é acadêmica. Todos esses elementos contribuem para a construção do ethos, condiciona o discurso e, consequentemente, a forma como o coenunciador irá elaborar a imagem do enunciador - o ethos discursivo.

Do mesmo modo, a cena englobante, no Facebook, dependerá do tipo de discurso contido na publicação (cômico, religioso, filosófico, dentre outros). A partir dele poderemos nos posicionar de uma ou outra forma diante do dito. A cena genérica, nessa rede social, corresponde ao gênero publicação em rede social virtual. E a cenografia, por sua vez, vai depender da que o enunciador criar, pois levando em consideração o caráter desse site, o coenunciador tende a posicionar-se de forma descontraída diante das enunciações que circulam nesse ambiente. Embora a cena englobante possa ser composta por discursos "sérios" como os de cunho comercial, educacional, informativo, político, a priori, não há obrigatoriedade de que tudo que circule seja real ou verídico, daí a forte presença de memes e das chamadas fake news. No entanto, o enunciador poderá sair desse espaço descontraído, ao tratar de assuntos de utilidade pública ou compartilhar uma notícia que circulou em um jornal, por exemplo.

Abordando brevemente o funcionamento do Facebook, no tocante ao aspecto discursivo-interacional, essa rede social é caracterizada como um ambiente em que, de acordo com Emediato (2015), há a ocorrência de: (i) interação entre códigos semiológicos, em especial, a verbo-visualidade; (ii) modalidades de interação que permitem o dialogismo interlocutivo e a aproximação das formas dialogais, proporcionando a copresença espacial mediante as ações de publicar, curtir, comentar e compartilhar; e (iii) organização interacional ou conversacional cujos participantes são o enunciador ou locutor, o coenunciador ou alocutário e um terceiro destinatário indireto de natureza coletiva.

É por meio dos atos de publicar, de curtir, de comentar e de compartilhar que os participantes da cena de enunciação realizam as interações no Facebook, mas é importante observarmos que cada uma dessas ações apresenta concepções próprias. Conforme a maneira como o discurso impacta o coenunciador, ele poderá suscitar reações distintas que, por sua vez, poderão ser manifestadas por ações que expressem seu impacto e a adesão ou rechaço desse coenunciador. Nesse contexto, passamos a observar a propriedade de tais ações: publicação, atos de curtir, comentar e compartilhar.

Podemos dizer que a interação no Facebook se inicia com a publicação. É a partir dela que o enunciador irá manifestar uma opinião, um acontecimento, abrindo, então, espaço para o coenunciador entrar na cena, por meio do ato de curtir, caracterizado como um ato kinésico, em regra, representativo de "uma apreciação implícita de cunho eletrônico, ou seja, trata-se de um sinal eletrônico que significa, em geral, um ato apreciativo positivo, mas não-verbal" (EMEDIATO, 2015, p. 174). No entanto, posteriormente, outros sinais passaram a fazer parte das reações gestuais eletrônicas, de modo que a permitir também apreciações negativas (Figura 1).

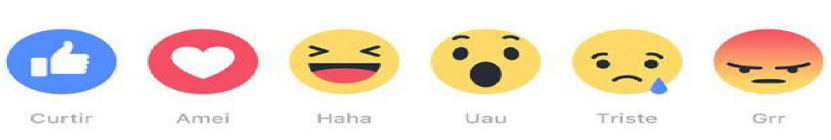

Figura 1. Atos knésicos do Facebook Fonte: Site G1.2

Já o ato de comentar, ao contrário do curtir e os demais atos gestuais eletrônicos, é um ato mais complexo e constitui uma resposta à publicação com caráter verbal. Por meio dela, o coenunciador expressa "uma apreciação positiva, negativa ou um julgamento axiológico, uma concordância ou uma discordância, conforme o caso" (EMEDIATO, 2015, p. 174).

No compartilhamento, por sua vez, o coenunciador, partindo da publicação do enunciador, replica-a. Essa replicação pode ser considerada, segundo Emediato (2015, p. 175), uma "adesão mais intensa, já que, além de expressar concordância com a publicação, o interlocutor se associa, ou seja, adere à publicação e tem interesse particular em amplificar a sua divulgação", ou mesmo uma discordância, em que o coenunciador se utiliza da publicação do enunciador para contextualizar um posicionamento distinto do tomado no discurso do enunciador.

\section{Canetas desmanipuladora e desesquerdizadora: a construção do ethos no discurso político}

A análise proposta neste artigo parte de publicações realizadas em duas páginas do Facebook que fazem oposição a manchetes e a conteúdos da mídia jornalística brasileira. A página Caneta desmanipuladora propõe-se, de acordo com o que difunde na mencionada rede social, a "esclarecer" o discurso de grandes jornais de circulação em âmbito nacional, mostrando outras formas de lê-lo e de compreendê-lo, no intuito de fazer o coenunciador, eventual leitor de tais periódicos, não tomar como verdade o dito, apontando o que considera como manipulação da notícia. A página Caneta desesquerdizadora, mais que a intenção de "esclarecer" o coenunciador, operando da mesma forma que aquela, posiciona-se explicitamente

\footnotetext{
2 Disponível em: <http://g1.globo.com/tecnologia/noticia/2016/02/ facebook-libera-cinco-novos-botoes-alternativos-ao-curtir.html>. Acesso em: 05 abr. 2018
} 
contra periódicos de cujas convicções político-partidárias não compartilha. Assim, selecionadas algumas publicações divulgadas na timeline de ambas as páginas, procedemos com uma análise, a fim de verificarmos como se dá a construção do ethos, a partir dos discursos que compõem tais publicações.

Conforme apresentamos na seção anterior, Maingueneau (2014) entende que, ao produzir o seu discurso escrito ou oral, o enunciador, por meio de pistas enunciativas, permite que o coenunciador construa o ethos desse enunciador. Para tanto, como procedem as páginas Caneta desmanipuladora e Caneta desesquerdizadora?

Verificando a seção "sobre" da página Caneta desmanipuladora, observamos o seguinte ethos dito - identificado a partir do que o enunciador fala de si (Figura 2): "traduzindo Midiês", o que corresponde, em consonância com o proposto pela página, a retirar um sentido outro que não seja aquele divulgado pela mídia, descobrir a intenção de adulterar a informação, desmanipulando - termo da página - os conteúdos dos periódicos. Notemos, porém, que em termos de eficácia e de impacto perante o coenunciador, o ethos dito não tem a força do ethos discursivo.

A explicitação de ideias e a forma como elas são produzidas produzem um efeito muito maior no coenunciador que, confrontando ambos planos dos ethé, confirmará a coerência entre eles ou não. No caso da página Caneta desmanipuladora, para aferirmos a confirmação do ethos dito pelo discursivo, selecionamos, na timeline da página Caneta desmanipuladora, algumas publicações.

A enunciação da Figura 3 traz uma foto da primeira página da edição veiculada na mesma data, do jornal Folha de S. Paulo, cuja chamada principal é a seguinte: "Comandante do Exército diz que repudia a impunidade", sendo que a expressão "diz que repudia a impunidade" está riscada de vermelho, apresentando em substituição "PRESSIONA O STF" (em caixa alta e em vermelho), provocando o efeito de correção de um termo pelo outro.

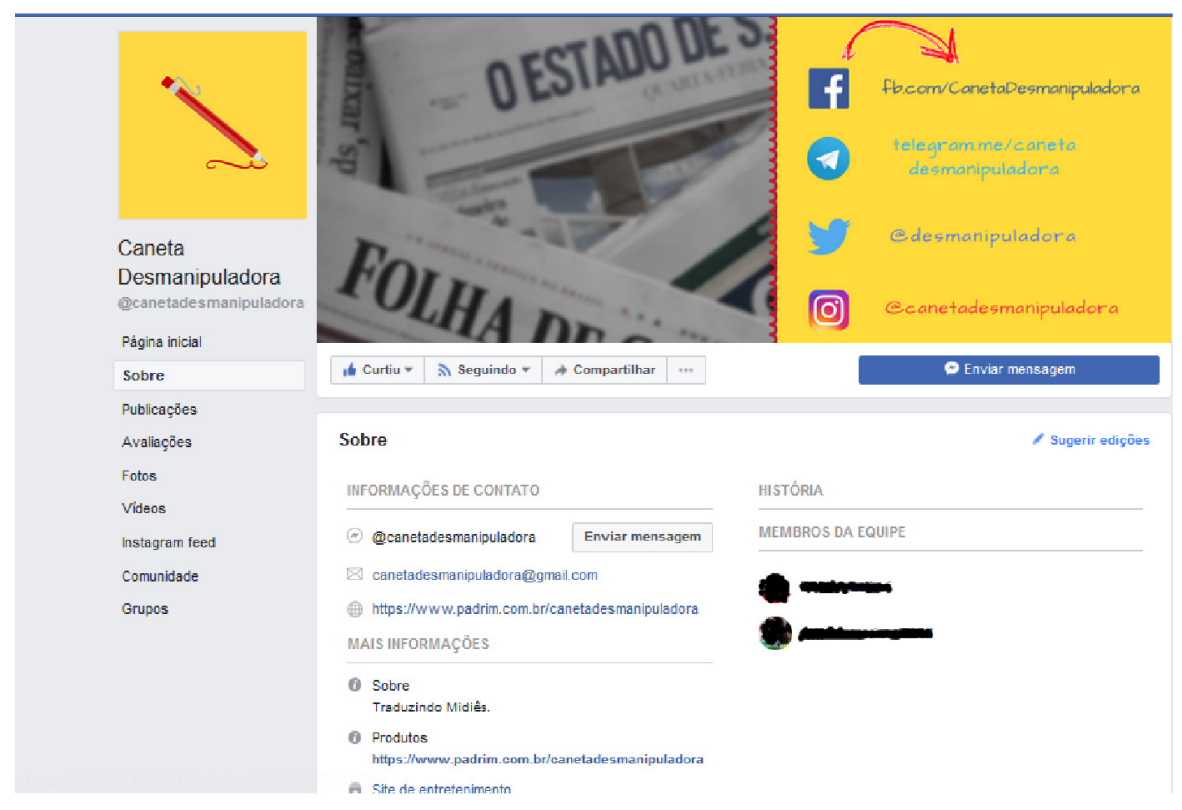

Figura 2. Seção "sobre" da página Caneta desmanipuladora (ethos dito) Fonte: Facebook.

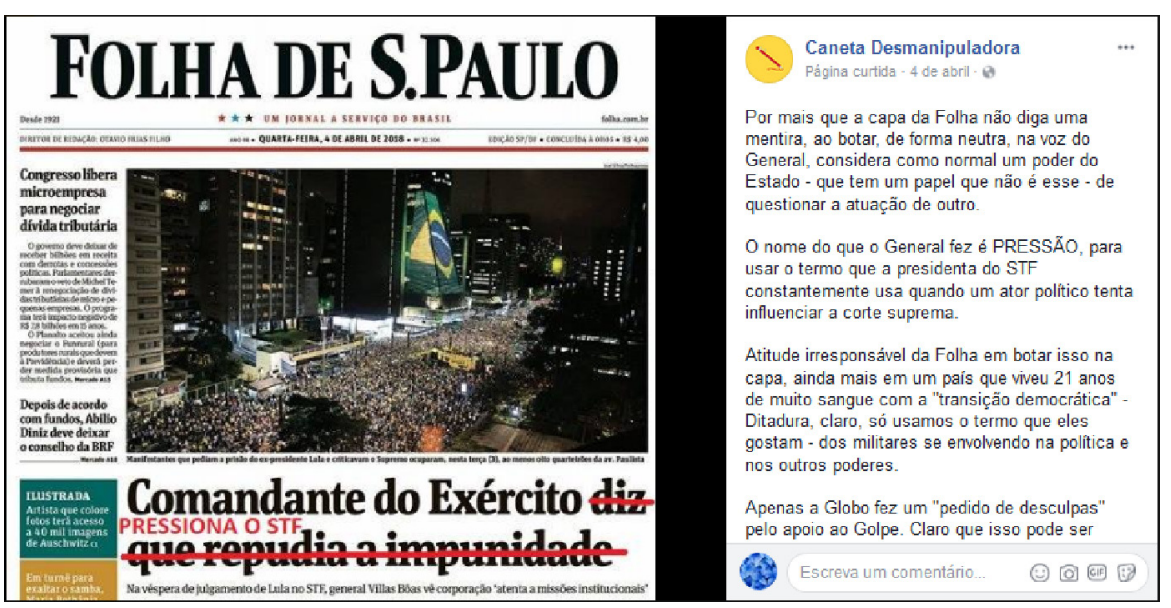

Figura 3. Publicação na timeline em 04 abr. 2018

Fonte: Facebook. 
Além da materialidade verbo-visual, o post apresenta um texto em que critica a suposta neutralidade do jornal, remetendo o artifício utilizado a situações análogas que se deram durante a Ditadura Militar vivenciada no Brasil:

Por mais que a capa da Folha não diga uma mentira, ao botar, de forma neutra, na voz do General, considera como normal um poder do Estado - que tem um papel que não é esse - de questionar a atuação de outro.

O nome do que o General fez é PRESSÃO, para usar o termo que a presidenta do STF constantemente usa quando um ator político tenta influenciar a corte suprema. Atitude irresponsável da Folha em botar isso na capa, ainda mais em um país que viveu 21 anos de muito sangue com a "transição democrática" - Ditadura, claro, só usamos o termo que eles gostam - dos militares se envolvendo na política e nos outros poderes. Apenas a Globo fez um "pedido de desculpas" pelo apoio ao Golpe. Claro que isso pode ser questionado se é um pedido de desculpas de coração, mas jornais, como a Folha de São Paulo, nunca assumiram o sangue que tiveram nas mãos. É hora do jornalismo se posicionar para que não desande para a barbárie novamente.

Podem contar com a Caneta, estaremos aqui fazendo PRESSÃO contra aqueles que ameaçam a democracia. (CANETA DESMANIPULADORA).

Observando a estratégia da página para demonstrar a "desmanipulação", percebemos que ela se utiliza de procedimento semelhante ao das práticas escolares tradicionais, em que os professores assinalam os desvios dos alunos com caneta vermelha para fins de correção. Assim, ao riscar o trecho da manchete e ao sobrepor a expressão "PRESSIONA O STF", em vermelho, produz-se o mesmo efeito de correção e, quanto à construção da sua imagem, colabora para que o coenunciador elabore um ethos discursivo correspondente a um enunciador atualizado, historicamente situado e crítico, que percebe as estratégias da mídia para distorcer a "real informação" - conforme a concepção da página. Portanto, tem-se um enunciador que constrói uma imagem de competente, de uma autoridade para efetuar a correção, demonstrando discursivamente o "verdadeiro" sentido da notícia que foi adulterado pelos interesses da Folha de São Paulo, ao trazer um discurso esclarecedor, segundo o posicionamento a que a página adere. Além disso, é importante atentarmonos para o fato de que o enunciador, embora não explicite, constrói seu discurso pautado no Princípio Constitucional da Separação dos Poderes, previsto no artigo 20 da Carta Magna, o qual preconiza a independência e a harmonia entre os Poderes.

Nesse contexto, notamos o intuito de fazer com que o discurso empregado pelo periódico seja tomado como inadequado, e o discurso mascarado - criado a partir da "desmanipulação" - seja considerado o apropriado. O enunciado que acompanha a imagem tem o intuito de reforçar essa intenção, compondo uma formação discursiva, que, conforme Soares, Sella e Costa-Hübes (2013, p. 265), é "um conjunto de enunciados em que ocorre certa regularidade ou ordem discursiva, conjunto tido como convencionado" -, a qual repercute uma compreensão sobre o jornal como um periódico irresponsável. O ethos da página em análise compactua do posicionamento segundo o qual a mídia não possibilita uma informação diversificada e caracterizada por pontos de vista diferentes (LIPOVESTKY, 2004), mas uma abordagem enviesada numa concepção monolítica que precisa ser desmoralizada, daí repousa a função da página e sua missão esclarecedora.

A segunda publicação que selecionamos (Figura 4) não apresenta os mesmos recursos "desmanipuladores" empregados na anterior. Neste post, a página apresenta

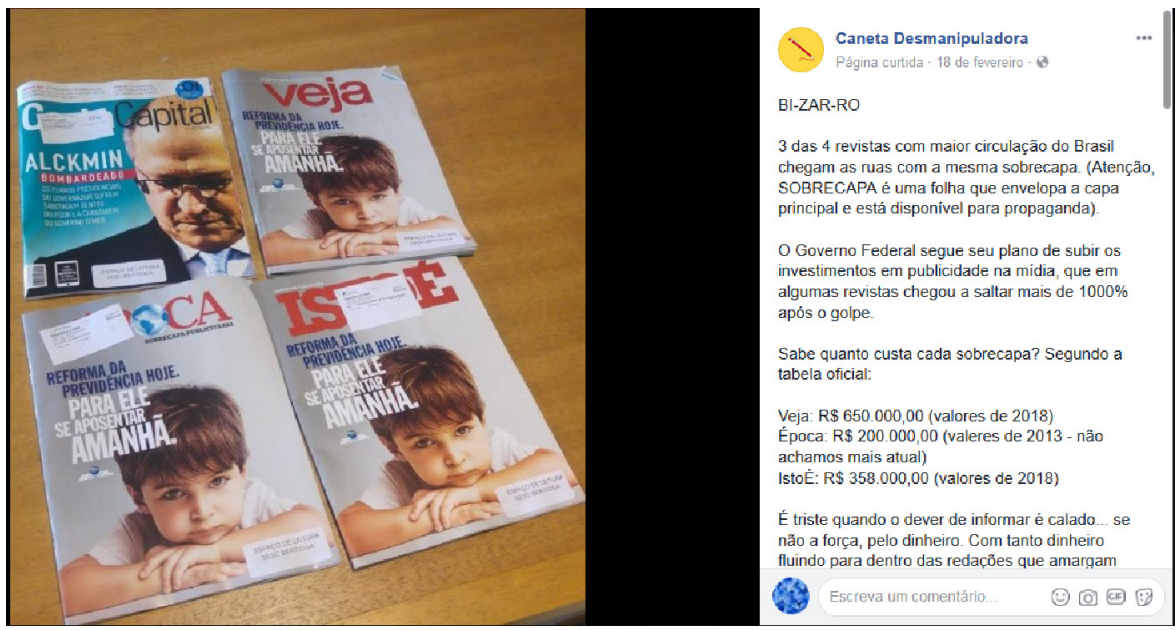

Figura 4. Publicação na timeline em 18 fev. 2018 Fonte: Facebook. 
uma foto com a imagem da sobrecapa das quatro maiores revistas semanais do Brasil (Carta Capital, Veja, Época e Isto é), publicadas no mesmo período. O efeito da foto, por si só, causa estranhamento por parte do coenunciador pelo fato de três das quatro revistas apresentarem sobrecapas idênticas com a mesma chamada: "Reforma da previdência hoje, para ele se aposentar amanhã".

No texto verbal que acompanha a imagem, o enunciador constrói o seu discurso atentando o coeunciador para a possibilidade de utilização de sobrecapa como propaganda, para, em seguida, apontar o aumento de investimentos em publicidade pelo Governo Federal. Na sequência, mostra os valores que as revistas cobram pela sobrecapa como veículo de propaganda. Por fim, conclui a enunciação com dois parágrafos, ancorando-se na ideia de que a imprensa brasileira é imparcial e, portanto, não confiável:

É triste quando o dever de informar é calado... se não a força, pelo dinheiro. Com tanto dinheiro fluindo para dentro das redações que amargam baixas vendas e tiveram demissões de setores inteiros, o apoio político a uma agenda é feito com o nosso dinheiro.

Não que o governo não deva publicitar o que está sendo feito. Mas infelizmente o que vemos é uma concorrência desleal com a compra do silêncio quando não do apoio - de colunistas, jornalistas e outros istas para forçar aprovação de algo impopular e que não tem votos para passar (CANETA DESMANIPULADORA).

As expressões "dever de informar é calado", "compra do silêncio" empregadas na enunciação colaboram para a "desmanipulação" visada pelo enunciador, não somente em relação às grandes mídias, mas também em

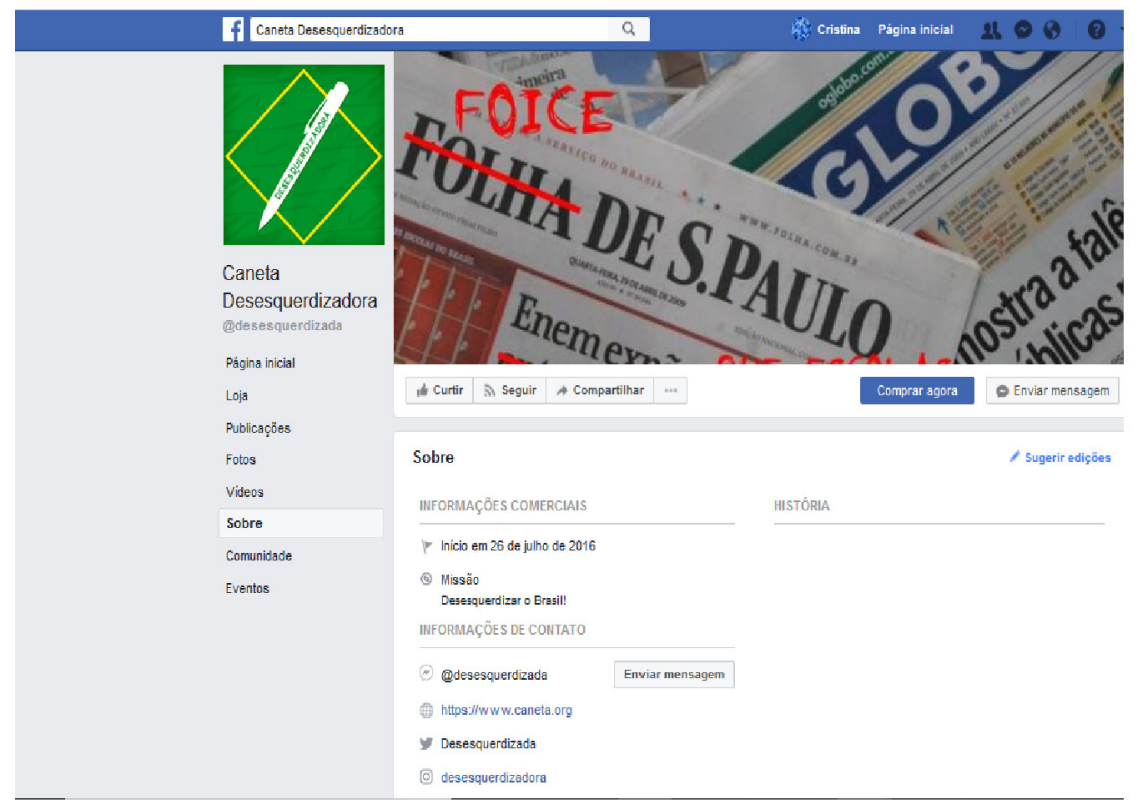

relação ao Governo Federal, na medida em que, somadas à constatação do grande investimento realizado em propaganda, põe em xeque a confiabilidade da população em relação ao plano de reforma previdenciária do Governo - uma vez que abre espaço para questionamentos tais como: "Por que investir tanto em propaganda se a reforma seria benéfica?", "Se estamos em crise, não seria melhor investir em outros setores mais urgentes que não a publicidade?". O ethos da página em estudo alinha-se à imagem de um enunciador que busca desmascarar os interesses partidários dos veículos da mídia corporativa, os quais estão a favor de conveniências de um grupo específico. De acordo com Lima (2004), diversos fatores contribuem para a concentração da propriedade dos meios de comunicação no Brasil, a exemplo da ineficácia dos dispositivos legais que deveriam restringir a participação societária e de grandes conglomerados empresariais nas concessões públicas dos veículos de comunicação no país.

Essa enunciação da página Caneta desmanipuladora, como a primeira, confirma o ethos dito - "traduzindo o Midiês" -, o que suscita no coenunciador sua adesão, fazendo-o conceber as enunciações das grandes mídias, no mínimo, com desconfiança, para não dizer com total falta de credibilidade. $O$ analista o verá como uma verdade situada em uma determinada comunidade linguística, ou seja, uma enunciação emitida por "enunciadores de um mesmo tipo de discurso [...], que partilham certo número de modos de vida, de normas etc." (SOARES; SELLA; COSTA-HÜBES, 2013, p. 276) -, no caso da página em estudo, enunciadores que apresentam um posicionamento opositor aos chamados "grandes conglomerados", que se situam politicamente a favor da situação vigente.

Partindo para a análise das enunciações da página Caneta desesquerdizadora, identificamos como ethos dito (Figura 5) a missão que a página se propõe, em consonância com o próprio nome, "desesquerdizar o Brasil", significando que o enunciador se mostra como posicionado politicamente contra a ideologia "da esquerda nacional", além de propagar uma ideia da esquerda como algo nocivo e danoso para o país.

Figura 5. Seção "sobre" da página Caneta desesquerdizadora (ethos dito) Fonte: Facebook. 
A página tem como objetivo criticar conteúdos que circulam em sites de notícias e em jornais (suporte físico), no sentido de retirar qualquer efeito discursivo de tendência "esquerdista", bem como replicar publicações próprias divulgadas em outra rede social, o Twitter, produzindo discursos de oposição aos partidos políticos de esquerda, especialmente contra o Partido dos Trabalhadores (PT), contra o ex-Presidente Luís Inácio Lula da Silva, o Lula, e seus simpatizantes.

$\mathrm{Na}$ foto da capa (Figura 5), o enunciador da Caneta desesquerdizadora, ao contrário do que faz o da página Caneta desmanipuladora, que apenas traz a imagem de jornais de grande circulação nacional, além de "desesquerdizar" a manchete da primeira página do jornal Folha de São Paulo, também tacha o periódico como de esquerda, ao substituir o termo "Folha" por "Foice", o que pode gerar no coenunciador da página em foco uma impressão sobre o jornal como sendo tendencioso e imparcial, dado que atende aos anseios comunistas personificados em toda a memória e o imaginário social relativos ao termo e ao objeto "foice".

O post (Figura 6) publicado na timeline da página utiliza o mesmo recurso que o empregado pela página Caneta desmanipuladora: o de riscar de vermelho os termos do site de notícias, especialmente a manchete, substituindo-os por expressões que possibilitam um novo sentido de acordo com o posicionamento defendido pelo enunciador.

A enunciação, que acompanha a imagem - "O G1 conseguiu uma proeza: inverter totalmente a notícia na manchete, transformando a esquerda que fez o fichamento em vítima! Caneta Desesquerdizadora neles!" -, reforça o sentido que a página desejou conferir à manchete após a sua "correção", trazendo a ideia de que a ação de formular uma planilha ou lista foi realizada por estudantes da esquerda, e não o contrário.

Ocorre que o termo "maconheiro esquerdista" apresentado na manchete do site de notícias também faz parte da lista - objeto da matéria jornalística. Ao retirar a expressão mencionada, riscando-a de vermelho, a página leva o coenunciador a crer que esse termo foi adotado pelo site de notícias, portanto, não estava na lista, o que não é a realidade. A expressão "maconheiro esquerdista" está, de fato, na planilha elaborada pelos alunos, assim como as demais que foram acrescentadas também de vermelho.

Ainda é importante notar que a manchete gerada com a "desesquerdização" da página: "Coletivo petista formado por alunos de direito da USP ficha calouros: judeu, crente, liberal de M..." torna a ação dos criadores da lista ainda mais grave do que já é em razão do emprego do verbo "fichar", sinônimo de "enquadrar", "atribuir crime", segundo a gíria policial.

O tom enunciativo, segundo Maingueneau (2016, p. 72), "implica uma determinação do corpo do enunciador (e não, bem entendido, do corpo do autor efetivo). Assim, a leitura faz emergir uma origem enunciativa, uma instância subjetiva encarnada que exerce o papel do fiador". O fiador, por sua vez, é investido de caráter (dimensão psicológica do ethos) e corporalidade (dimensão física do ethos), os quais se apoiam, "[...] sobre um conjunto difuso de representações sociais valorizadas ou desvalorizadas, de estereótipos sobre os quais a enunciação se apoia e, por sua vez, contribui para reforçar ou transformar" (2016, p. 72). Nesse contexto, podemos dizer que o caráter e a corporalidade do fiador desta página são bastante próximos do fiador da página anteriormente analisada.

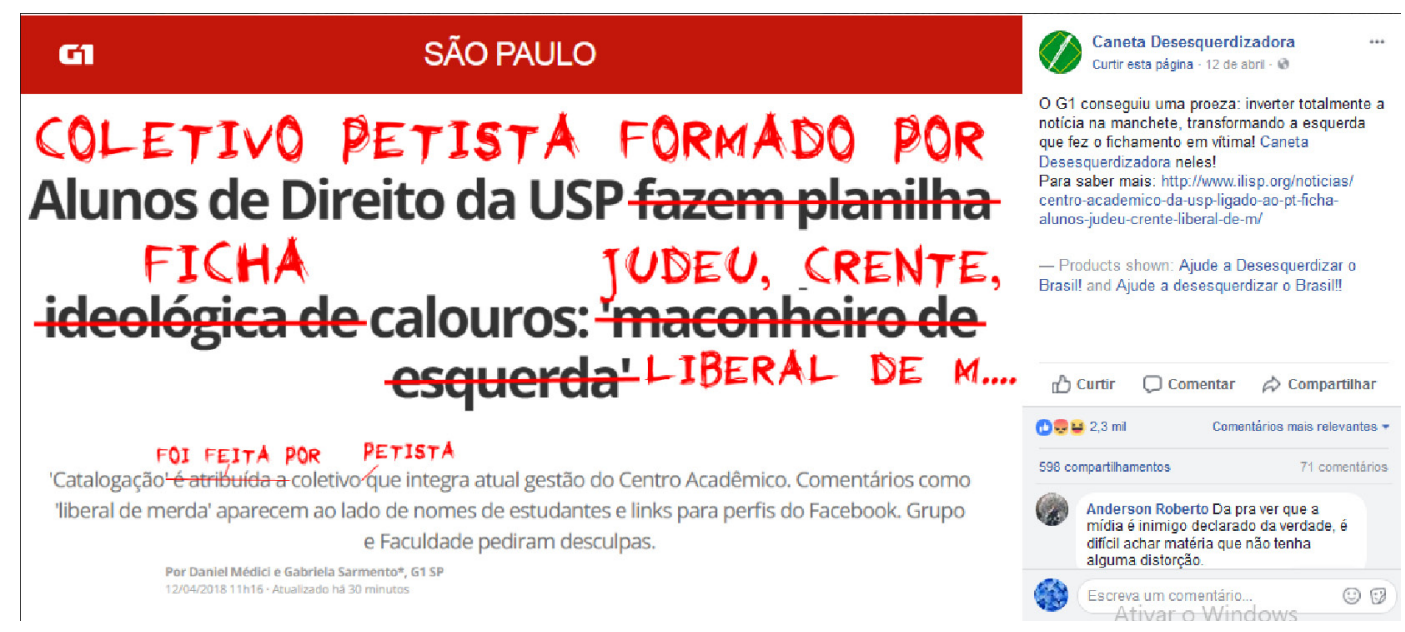

Figura 6. Publicação na timeline em 12 abr. 2018 Fonte: Facebook. 
Todavia, estudando outras publicações da página Caneta desesquerdizadora, ao contrário da primeira, encontramos um número significativo de enunciados que não trazem a "correção desesquerdizadora" como a empregada na Figura 6, mas que se referem ao compartilhamento de enunciações realizadas pelo mesmo enunciador no Twitter (Figura 7). Tais enunciações, muitas vezes, explicitam um tom mais agressivo, provocando um apagamento do que poderia ser considerado um enunciador que pretende desempenhar uma utilidade pública - a ação de mostrar um outro discurso que o a priori divulgado pela notícia de um site ou de um periódico -, ao passo que compromete o efeito das "correções" realizadas em outras publicações. Vejamos a publicação a seguir.
'Eu Odeio a Classe Média' Chauí (sic) para tentar explicar a Internet. Este foi o resultado." (CANETA DESESQUEDIZADORA), percebemos mais uma vez a configuração de uma enunciação que contribui para a construção de um ethos ordinário, no sentido de não representar uma autoridade acerca daquilo que enuncia. Ao se referir jocosamente à reconhecida estudiosa e autora de obras filosóficas como "jurássica", deixa evidente o cunho descomprometido e rude de sua enunciação.

O ethos dito do enunciador da Caneta desesquerdizadora, de acordo com o que já apresentamos, é "desesquerdizar o Brasil", no entanto, o ethos discursivo desse enunciador, a partir das enunciações analisadas, não é dotado de um fiador coerente que se mostre apto à pretensão dita. Se o efeito pretendido da ação de "deserquerdizar" for conquistar novos simpatizantes, provocar novas adesões, modificando o posicionamento ideológico dos coenunciadores de suas enunciações, a falta de enunciados calcados em saberes que escapem do senso comum, o emprego de termos infames e de argumentos simplistas apresentam-se como elementos para a construção de um ethos que não será capaz de provocar o resultado buscado pelo ethos dito. O máximo que alcançará, sempre considerando o corpus deste trabalho, será provocar a adesão, além dos seguidores da página, daquele público que já comunga com o seu

Figura 7. Publicação na timeline em 09 abr. 2018 Fonte: Facebook.

Os termos pejorativos "vagabundos", "quadrilha", "cretino", utilizados pelo enunciador na publicação da Figura 7, conferem ao enunciador pistas enunciativas que colaboram para a construção de um ethos distinto do que poderia ser elaborado somente a partir de enunciações como a da Figura 6, ou seja, um ethos discursivo cujo caráter e corporalidade são mais próximos de um fiador próximo de uma imagem bronca, rudimentar, de uma opinião rasa que não se afasta do senso comum. Como podemos ver, o discurso passional, senão agressivo, da página ora estudada, assim, retira a autoridade do enunciador. ${ }^{3}$

Observando a publicação da Figura 8 também da Caneta desesquerdizadora, composta por o que se percebe ser um trecho recortado de um vídeo maior em que aparece a filósofa Marilena Chaui e por um enunciado - "Colocaram a jurássica socialista Marilena

\footnotetext{
3 Amossy (2016, p. 16) explica que "[...] o enunciador deve se conferir, e conferir a seu destinatário, certo status para legitimar seu dizer: ele se outorga no discurso uma posição institucional e marca sua relação com um saber". No entanto, tratando-se da página Caneta desesquerdizadora, isso não ocorre.
}

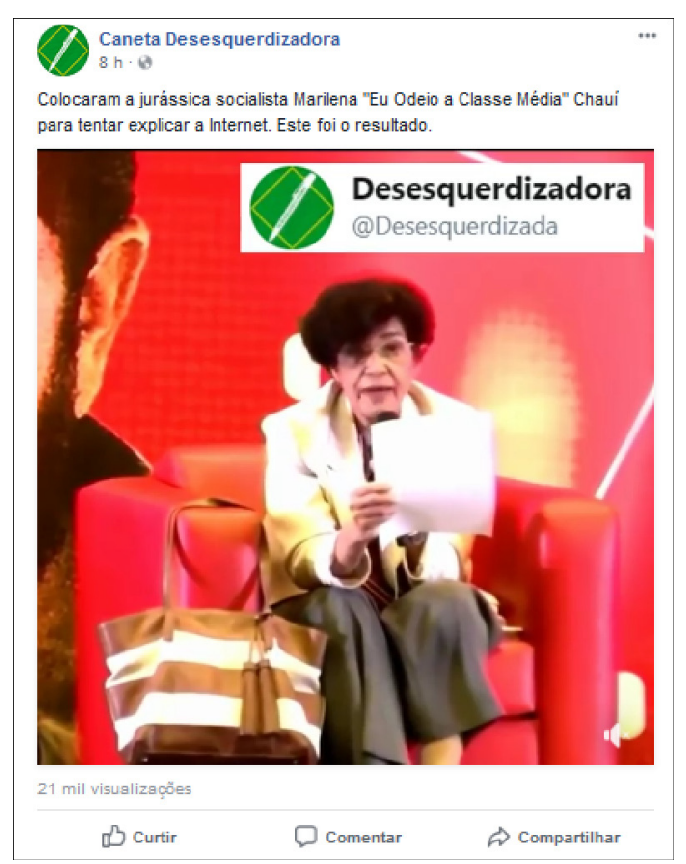

Figura 8. Publicação na timeline em 16 abr. 2018 Fonte: Caneta deserquedizadora. 
posicionamento ideológico e com a maneira de enunciar típica da Caneta desesquerdizadora.

\section{Considerações finais}

A partir da análise das páginas Caneta desmanipuladora e Caneta desesquerdizadora, percebemos como os dois enunciadores, que, a priori, apresentam propostas semelhantes - mostrar um discurso outro que subjaz manchetes de jornais, revistas e sites de notícias veiculam -, podem criar imagens de si distintas, a partir do ethos discursivo. Inicialmente, convém aventar que as páginas compartilham de posicionamentos políticos distintos, demonstrando que os efeitos da utilização de uma mesma plataforma de comunicação podem variar substancialmente (MARQUES, 2016), de maneira a atestar a heterogeneidade das interações travadas na rede.

Nesse sentido, o enunciador da página Caneta desmanipuladora, como pudemos ver na análise, traz como proposta "desmanipular" a grande mídia, o que significa, em outras palavras, trazer uma nova leitura que suscite dúvidas sobre a parcialidade da manchete jornalista posta em circulação pelos grandes jornais nacionais, configurando o seu ethos dito. Para atender a essa proposta, esse enunciador utiliza como estratégia publicar, em sua timeline, imagens de notícias que buscam "desmanipular", utilizando recursos como riscar com traço vermelho termos que considera manipuladores, substituindo-os por outros termos entendidos como os mais adequados, os quais são escritos sobre aqueles também em vermelho, numa tentativa de recriar uma verdade para os fatos noticiados.

Acompanhando as imagens, o enunciador traz uma enunciação de sua autoria, buscando reforçar o efeito "desmanipulador" pretendido, seja por meio de uma explicação ou de uma contextualização, conferindo ao coenunciador elementos para a construção do ethos discursivo daquele, qual seja: uma autoridade intelectualizada e com conhecimento sobre aquilo que diz, de modo que apresenta capacidade para realizar determinadas correções, de maneira a desnaturalizar uma dada verdade midiática. Assim, confrontando o ethos dito da página em tela com o discursivo, podemos concluir pela coerência do enunciador no seu modo de se mostrar em relação ao que diz ser, ou seja, a página Caneta desmanipuladora apresenta um ethos dito coerente com o ethos discursivo.

Já em relação ao enunciador da página Caneta desesquerdizadora verificamos, em nossa análise, que tal coerência não se dá, tendo em vista que, apesar de esse enunciador trazer como proposta "desesquerdizar o Brasil", utilizando os mesmos recursos que a Caneta desmanipuladora - publicar imagens de notícias que visa a "desesquerdizar", utilizando o traço vermelho e a substituição de termos por outros que entende como adequados também em cor vermelha -, ao enunciar, seja ao lado das imagens das manchetes que busca "corrigir", seja nas enunciações que se referem à republicação de postagens que realiza no Twitter, a Caneta desesquerdizadora perde o tom professoral. Isso se dá em razão do uso de um linguajar chulo e argumentos calcados nas naturalizações do senso comum. Desse modo, o coenunciador, ao confrontar ambos os ethé o dito e o discursivo - desse enunciador perceberá que um não confirma o outro, em face da contradição que apresentam.

Enfim, as duas páginas, cada uma a sua maneira, emolduram ethé confluentes com o papel ativo dos usuários das mídias digitais frente à produção jornalística de instituições de comunicações. Embalados por preferências político-partidárias aparentemente díspares, as páginas investigadas ilustram as relações de força responsáveis pelos discursos políticos engendrados no Facebook, que, a despeito de todas as incongruências e contradições, representa a ágora do debate público atual, numa relação que parece desafiar a preponderância informacional dos tradicionais veículos de comunicação.

\section{Referências}

AMOSSY, Ruth. Introdução - Da noção retórica de ethos à análise do discurso. In: AMOSSY, Ruth (Org.). Imagens de si no discurso: a construção do ethos. São Paulo: Contexto, 2016. p. 9-28.

BOYD, Danah M.; ELLISON, Nicole B. Social network sites: definition, history, and scholarship. Journal of ComputerMediated Communication, v. 13, n. 1, p.210-230, out. 2007. Disponível em: <http://onlinelibrary.wiley.com/doi/10.1111/ j.1083-6101.2007.00393.x/full>. Acesso em: 29 mar. 2018.

COUTO, Edvaldo Souza. Narrativas pessoais nas redes sociais digitais. In: CORACINI, Maria José; CARMAGNANI, Anna Maria Grammatico (Org.). Mídia, exclusão e ensino: dilemas e desafios na contemporaneidade. Campinas: Pontes Editores, 2014. p. 281-295

EMEDIATO, Wander. Discurso e web: as múltiplas faces do Facebook. Revista da ABRALIN, Paraná, v. 14, n. 2, p. 171-192, jul. 2015.

JENKINS, Henry. Cultura da convergência. Trad. Suzana Alexandria. São Paulo: Aleph, 2009.

LEMOS, André. Cibercultura: alguns pontos para compreender a nossa época. In: LEMOS, André; CUNHA, Paulo (Org.) Olhares sobre a cibercultura. Porto Alegre: Sulina, 2003. p. 11-23.

LEMOS, André. Cibercultura: tecnologia e vida social na cultura contemporânea. Porto Alegre: Sulina, 2010.

LIMA, Venâncio Artur de. Mídia: teoria e política. 2. ed. São Paulo: Fundação Perseu Abramo, 2004. 
LIPOVETSKY, Gilles. Os tempos hipermodernos. Trad. Mário Vilela. São Paulo: Barcarolla, 2004.

MAINGUENEAU, Dominique. Análise de textos de comunicação. São Paulo: Cortez, 2004.

MAINGUENEAU, Dominique. Ethos, cenografia, incorporação. In: AMOSSY, Ruth (Org.). Imagens de si no discurso: a construção do ethos. São Paulo: Contexto, 2016. p. 69-92.

MARQUES, Francisco Paulo Jamil Almeida. Ciberpolitica: conceitos e experiências. Salvador: EDUFBA, 2016.

RECUERO, Raquel. Redes sociais na internet. Porto Alegre: Sulina: 2010.
SOARES, Alexandre Ferrari; SELLA, Aparecida Feola; COSTA-HÜBES, Terezinha. Maingueneau. In: OLIVEIRA, Luciano Amaral (Org.). Estudos do discurso: perspectivas teóricas. São Paulo: Parábola Editorial, 2013. p.261-279.

Recebido: $28 / 04 / 2018$

Aprovado: 19/07/2018

(D) CRISTINA ROTHIER DUARTE <cristinarothier@hotmail.com> Mestranda, Universidade Federal da Paraíba, João Pessoa, Paraíba, Brasil. (D) FRANCISCO VIEIRA DA SILVA < francisco.vieiras@ufersa.edu.br> Professor, Universidade Federal Rural do Semi-Árido, Mossoró, Rio Grande do Norte, Brasil. 